\title{
APRENDIZAGEM SOLIDÁRIA E A RESPONSABILIDADE SOCIAL PARA OUTRO MUNDO POSSÍVEL
}

Katia Gonçalves Mori ${ }^{52}$

\begin{abstract}
Resumo
Esse início de século tem sido marcado por incessantes conquistas das ciências e das tecnologias, de conexão global, de comunicação, de produção e de consumo. Ao mesmo tempo, antigos problemas humanitários ainda são temas que persistem e ameaçam a humanidade, nos lembrando da importância da reconstrução permanente de um projeto ético de sociedade local e global. Nesse cenário, a produção de conhecimento é fundamental. Propostas formativas baseadas em um currículo crítico, desenvolvido a partir do enfrentamento de problemas sociais reais é a aposta da aprendizagem solidária (aprendizagem e serviço solidário). Este artigo pretende contribuir para a compreensão desse conceito. Para isso, irá definir solidariedade e aprendizagem, buscando pontuar as diferenças entre caridade, assistencialismo e solidariedade, bem como clarear as diferenças entre algumas atividades de intervenção social durante os processos formativos. Traz ainda a importância de se costurar a aprendizagem solidária ao conceito de responsabilidade social universitária para outro mundo possível.
\end{abstract}

Palavras-chave: Aprendizagem solidária. Aprendizagem e serviço solidário. Responsabilidade social universitária. Educação para o século 21. Práticas pedagógicas.

\section{SERVICE LEARNING E RESPONSABILITÀ SOCIALE PER UN ALTRO MONDO POSSIBILE}

\section{Sintesi}

Questo inizio di secolo è stato caratterizzato da incessanti conquiste delle scienze e delle tecnologie, da una connessione globale, da comunicazione, da produzione e consumo. Allo stesso tempo, i vecchi problemi dell'umanità sono ancora temi che persistono e minacciano l'umanità, ricordandoci l'importanza della ricostruzione permanente di un progetto etico della società locale e globale. In questo scenario, la produzione di conoscenza è fondamentale. Proposte formative basate su un curriculum critico, sviluppato a partire dall'affrontare problemi sociali reali è la scommessa del Service Learning (apprendimento e servizio solidale). Questo articolo cerca di contribuire alla comprensione di questo concetto. A tal fine, definirà la solidarietà e l'apprendimento, cercando di evidenziare le differenze tra carità, assistenzialismo e solidarietà, oltre a chiarire le differenze tra alcune attività di intervento sociale durante i processi formativi. Riporta anche l'importanza di unire il Service Learning al concetto di responsabilità sociale dell'università per un altro mondo possibile.

\footnotetext{
52 Mestre e Doutora em Educação: Currículo pela Pontifícia Universidade Católica de São Paulo, consultora e membro da Red Iberoamericana de Aprendizaje-Servicio desde 2005 e do Comitê Executivo da Rede Brasileira de Aprendizagem Solidária desde 2017.
} 
Parole chiave: Service Learning. Apprendimento e Servizio Solidale. Responsabilità sociale universitaria. Educazione per il XXI secolo. Pratiche pedagogiche.

\title{
SERVICE LEARNING AND SOCIAL RESPONSIBILITY FOR ANOTHER POSSIBLE WORLD
}

\begin{abstract}
This beginning of the century has been characterized by incessant achievements of science and technology, by a global connection, by communication and by production and consumption. At the same time, the old problems of humanity are still themes that persist and threaten humanity, reminding us of the importance of the permanent reconstruction of an ethical project of local and global society. In this scenario, the production of knowledge is fundamental. Educational proposals based on a critical curriculum and developed starting from tackling real social problems are the bet of Service Learning (Learning and Solidarity Service). This article tries to contribute to the understanding of this concept. To this end, it will define solidarity and learning, trying to highlight the differences between charity, welfare and solidarity, as well as clarifying the differences between some social intervention activities during the educational processes. It also reports the importance of combining Service Learning with the university's concept of social responsibility for another possible world.
\end{abstract}

Keywords: Service Learning. Learning and Solidarity Service. University social responsibility. Education for the 21st century. Pedagogical practices.

\section{Introdução}

Segundo o último relatório sobre a Segurança Alimentar e Nutrição das Nações Unidas, relativo a 2017, há cerca de 821 milhões de pessoas no mundo passando fome, a maior parte das quais na África e na América do Sul, um número que tem aumentado há três anos consecutivos.

Em 2016, a Global Slavery Index estimou que exista 40,3 milhões de pessoas escravizadas no mundo, sendo que desse número, $71 \%$ são mulheres ${ }^{53}$. Dados divulgados pelo Observatório de Igualdade de Gênero da Comissão Econômica para a América Latina e o Caribe (CEPAL) denunciam que 2.795 mulheres foram assassinadas em 2017 por razões de gênero em 23 países da América Latina e do Caribe. Dessas, 1.133 vítimas foram confirmadas no Brasil.

\footnotetext{
${ }^{53}$ Para mais informações, acesse: https://www.globalslaveryindex.org/2018/findings/highlights/
} 
Num mundo bastante conturbado, as tecnologias e as ciências têm o poder de potencializar qualquer que seja o projeto de nação que se almeje. Se por um lado temos conquistado avanços científicos e tecnológicos com possibilidades de conexões em tempo real planetária e todos os seus benefícios, por outro alimentamos problemas humanitários milenares, como os citados acima, nos lembrando da importância da reconstrução permanente de um projeto ético de sociedade.

Nesse sentido, Boaventura de Souza Santos (SANTOS, 2009) nos alerta para o fato de estarmos caminhando, basicamente, entre duas formas de conhecimento, a que regula o status quo e viabiliza a reprodução das desigualdades; e a emancipadora, que considera o homem não enquanto objeto de um sistema hegemônico, mas como sujeito capaz de reconstruir sua própria história.

No projeto da modernidade podemos distinguir duas formas de conhecimento: o conhecimento-regulação cujo ponto de ignorância se designa por caos e cujo ponto de saber se designa por ordem, e o conhecimento-emancipação, cujo ponto de ignorância se designa por colonialismo e cujo ponto de saber se designa por solidariedade. Apesar de estas duas formas de conhecimento estarem ambas inscritas na matriz da modernidade eurocêntrica, a verdade é que o conhecimentoregulação veio a dominar totalmente o conhecimento-emancipação. Isto deveu-se ao modo como a ciência moderna se converteu em conhecimento hegemônico e se institucionalizou como tal.(SANTOS, 2009, p. 29)

Ao se considerar a construção do conhecimento o motor do processo formativo, não basta oferecer letramento nas diferentes linguagens (verbal, matemática, científica, midiática, cultural). É preciso que, de saída, o estudante aprenda a reconhecer no outro a possibilidade de elevá-lo da condição de objeto à condição de sujeito da sua própria história. Esse conhecimento-reconhecimento acontece mediante um diálogo multicultural que se enriquece na diversidade e na diferença, na horizontalidade das relações, na tolerância, no desejo de partilhar e afirmar a vida em sua plenitude (SANTOS, 2009; DUSSEL, 2007)

Leornardo Boff (BOFF 2005; 2006) aponta o intercâmbio, o respeito, a convivência, o estar junto e o cuidado com a "mãe-terra" como a única alternativa ao suicídio a que se propõe uma sociedade individualista e competitiva, advindos de uma massificação dos padrões que ditam o rumo do chamado "progresso": A negação ao diferente, ao tradicional, a pluralização perversa do individualismo, do consumo exagerado, efêmero e desnecessário. 
Como resposta a esse cenário, é preciso que haja uma proposta formativa para outro mundo possível. A educação precisa de espaços de aprendizagem que ensinem a indignar-se, a resolver problemas reais, a estar no mundo e fazer parte de sua transformação. Compreender a solidariedade enquanto conhecimento é fundamental nesse processo, pois permite um enredamento de saberes tramado a partir da afirmação das subjetividades. Umas das propostas que vem ao encontro de desenvolver práticas pedagógicas visando esse objetivo é a aprendizagem solidária.

\section{Aprendizagem solidária: um conceito em movimento}

Basicamente, aprendizagem solidária é um conceito vivo, em constante movimento e cunhado ao redor do mundo pela qual os estudantes são desafiados a utilizar os saberes aprendidos para resolver problemas sociais reais por eles identificados.

Mais do que preparar para o sucesso acadêmico, a proposta estimula os jovens a desenvolver determinadas atividades de intervenção social como estratégia formativa. Com isso, o aprendizado passa a ter mais significado e o envolvimento permite a articulação de diferentes competências fundamentais para a formação pessoal e social.

\section{Características da aprendizagem solidária}

A proposta de aprendizagem solidária pode ter diferenças e adequações regionais ${ }^{54}$, ela está inspirada nos conceitos de aprendizaje servicio (tais como vistos na Argentina, Espanha, Chile, Uruguai entre outros ${ }^{55}$ ) e service learning (Estados Unidos, Canadá ${ }^{56}$. Especialistas como Nieves Tapia (TAPIA, 2001; 2006) e Andrew Furco (FURCO, 2010) sugerem considerar algumas características que delimitam o seu contorno, tais como:

\footnotetext{
${ }^{54}$ Em 2017 um grupo de instituições da sociedade civil, instituições de ensino, organismos do governo lançaram a Rede Brasileira de Aprendizagem Solidária liderada até 2019 pelo CENPEC - Centro de Estudos e Pesquisas em Educação, Cultura e Ação Comunitária. Mais informações disponíveis em https://www.cenpec.org.br/?s=aprendizagem+solidaria. Acesso em 17/dez/2019.

55 Vide Red Iberoamericana de Aprendizaje y Servicio Solidario, disponível em http://www.clayss.org/redibero.html Esta rede é coordenada pelo CLAYSS - Centro Latino americano de aprendizaje y servicio solidario. O site é uma referência no tema com notícias, conteúdo e formação disponível em www.clayss.org.ar. Acesso em 24/jan/2020.

${ }^{56} \mathrm{Há}$ muitos institutos, universidades e escolas (especialmente do ensino médio) envolvidas em programas e projetos de service learning. Mais informações em ARSLCE (International Association for Research on Service-learning and Community Engagement - http://www.researchslce.org) e NYLC (National Youth Leadership Concil - https://www.nylc.org). Acesso em 24/jan/2020.
} 
- o protagonismo dos estudantes na proposição e participação em projetos de intervenção social orientados pelos professores, articulando-se intencionalmente aos conteúdos de aprendizagem (COSTA, 2000);

- a oportunidade de se passar de situações de aprendizagens mecânicas (memorização literal, aleatória) para as aprendizagens significativas (ressignificação de conhecimentos prévios), uma vez que o enfrentamento de problemas reais cria condições de repensar o que se sabe, compreender, mobilizar a vontade de aprender para enfrentar uma nova situação (MOREIRA, 2012);

- a integração com a comunidade, a construção do conhecimento que melhora a qualidade de educação e também atua de maneira socialmente responsável pela prática do fazer com em contraponto ao fazer para;

- a participação dos alunos de maneira responsável e ativa, nas quais os jovens se envolvem em todas as etapas do processo, colaborativamente (COSTA, 2000);

- as experiências de construção de conhecimento contextualizado, num processo onde a superação das dificuldades, os erros e imprevistos fortalecem a aprendizagem para a participação responsável na vida em sociedade (DEWEY, 1979);

- o direcionamento do foco pedagógico tanto ao desenvolvimento integral do aluno (cognitivo, socioemocional e ético) quanto na causa dos problemas para promover a transformação social desejada.

Indo além, outro aspecto fundamental é compreender os conceitos de "solidariedade" e "aprendizagem" que sustentam a proposta (TAPIA, 2001).

\section{Diferenças entre caridade, assistencialismo e solidariedade}

É comum haver apropriação dos termos caridade, assistencialismo e solidariedade, como se eles pudessem ser empregados como sinônimos, quando não são.

O termo caridade, do latim caritas, remete a ideia de amar a Deus e ao próximo e está associado à doação voluntária, desde atenção até ajuda material, financeira. A caridade pode acontecer de maneira individual ou quando motivada por grupos. Por ser um ato espontâneo geralmente ligado à bondade, ao amor ao próximo, visa confortar as populações carentes e atuar nos sintomas dos problemas sociais. Por estar ligada à oferta de doação, ocorre que sua prática vertical pode reforçar o status quo ou não contribuir para a transformação social desejada. Em outras palavras, se pensada a partir da bondade 
egocêntrica, do discurso demagogo de quem não quer de fato contribuir com a mudança frente à justiça social, do assistencialismo ingênuo, a caridade pode reforçar a desigualdade social e dar margens para a falsa filantropia (JORNAL DO BRASIL, 2007). Paulo Freire é critico da caridade por esses modelos não promoverem o enfrentamento da realidade, mas sim sua constatação (FREIRE, 1996; 2001).

No entanto, há na caridade a compreensão de amor ao próximo, que também é uma das premissas do Paradigma do Cuidado (TORO, 2014), o qual se propõe outro paradigma possível para a humanidade, o cuidar de si mesmo, do outro e do planeta. Cuando amamos, cuidamos, y cuando cuidamos, amamos. (TORO, 2014, p.1).

Para o autor, é preciso compreender que pertencemos da mesma forma ao meio ambiente e por isso temos que estar no mundo com os valores ajustados para o ganhaganha, o saber cuidar, o estar com o outro e com o planeta de maneira corresponsável, em oposição ao próprio sucesso e exploração. $\mathrm{O}$ amor aqui se refere ao cuidar para a sustentabilidade, para que todos tenham condições e responsabilidades. A compreensão conceitual do termo caridade numa atividade educativa precisa estar ajustada para não perpetuar a constatação dos problemas sociais com normalidade, para que o atendimento comunitário não colabore com a permanência das estruturas injustas. A prática educativa libertadora, tanto em Freire como em Toro, parte da amorisidade, mas com consciência crítica, condicionantes fundamentais para balizar a proposta de responsabilidade social em suas dimensões comunitárias e educativas.

O termo assistencialismo remete a propostas de assistência social. Tais ações são caracterizadas pela ideia de assistir, de servir aos menos favorecidos, em atividades descomprometidas com a responsabilidade de promover a transformação social. Pode-se dizer que, como a caridade, a intenção não está centrada em tratar o problema, mas sim de atender os efeitos sintomáticos mais urgentes, como a fome, o frio, a dor, o desamparo, entre outros.

Para Freire, o assistencialismo é um processo antidialógico, pois existe a partir de uma verticalidade entre quem recebe e quem doa, neutralizando as condições para que de fato o diálogo se estabeleça.

O assistencialismo, pela sua eficácia em estabelecer situações de dependência e de impedir que as pessoas exerçam a sua condição de serem sujeitos, inviabiliza a construção de uma vida de justiça e de dignidade humana, pois imobiliza a possibilidade de superação das condições de opressão, e, com isso, contribui fortemente para a desumanização dos seres humanos (FREIRE, 1982, p. 35) 
Há atividades fundamentais enquanto atendimento solidário emergencial, especialmente em momentos extraordinários como guerras, desastres ambientais, pandemias. A intencionalidade da ação comunitária e educativa precisa estar clara, visando garantir uma proposta afirmativa das condições de vida sem deixar de ser crítica e perene, com foco no fortalecimento das redes colaborativas de proteção e justiça social.

O termo solidariedade remete ao conceito francês solidariete e se refere à ideia de cuidado mútuo, de proteção de cada um para o bem de todos, de responsabilidade recíproca, denominada como solidariedade social.

A solidariedade parte da afirmação de cada sujeito, com suas crenças e valores. Sendo assim, ela fortalece a comunidade na medida em que mantém sadia a relação entre seus membros. Ser solidário é uma maneira eficiente de alimentar redes colaborativas para o enfrentamento de problemas que seriam impossíveis de serem resolvidos de imediato ou com respostas simplistas. A solidariedade pode acontecer tanto em problemas emergenciais quanto perenes, com visão crítica de que é preciso atuar nas duas frentes por melhorar de fato as condições sociais.

A solidariedade é a reconstrução dialética do conhecimento em contraponto ao conhecimento regulação. Ela parte da horizontalidade, da subjetividade do sujeito e promove a emancipação, respeitando as diferenças, a interculturalidade de maneira horizontal. Nesse sentido, SANTOS $(2007 ; 2010)$ compreende solidariedade enquanto conhecimento emancipação solidariedade.

Para criar experiências e didáticas de construção do conhecimento emancipação solidariedade, é preciso inferir não só na leitura de mundo na análise freiriana de que a realidade não é, mas, sobretudo, está sendo (FREIRE, 2006), mas também em atividades de intervenção nos territórios. Esse envolvimento é feito com escuta e diagnóstico da realidade local em diferentes níveis. Como a solidariedade envolve buscar compreender o problema e participar da solução de forma consciente junto à comunidade, ela reforça aaprendizagem mútua. Essas experiências caracterizam propostas de aprendizagem solidária.

Assim como demarcar o que se entende por solidariedade, é preciso qualificar aprendizagem na composição do conceito de aprendizagem solidária, pois nem toda atividade educativa que aborda aspectos relacionados à comunidade pode ser considerada uma prática de aprendizagem solidária. 


\section{Diferenças entre estudos sobre questões da atualidade, pesquisas de campo e aprendizagem solidária}

Podem ser considerados estudos sobre questões da atualidade ou ainda estudos ou pesquisas de campo aqueles feitos a partir de observações de fatos, fenômenos e/ou documentos. Considera-se um aspecto essencial coletar informações ou dados referentes a fatos observáveis para que seja possível registrar, analisar e interpretar, com base em fundamentação teórica que permita checar e buscar compreender o problema pesquisado (CHIZZOTTI, 1991). Nesse caso, tais atividades têm um caráter exploratório, promovem conhecimento, análises, os estudos podem ter uma ou mais disciplinas, podem servir de base para mais estudos e pesquisas, ou serem técnicas pedagógicas em contextos disciplinares diversos. No entanto, se não houver uma intervenção real para transformar a realidade observada, não se pode caracterizar essa atividade pedagógica como sendo uma proposta de aprendizagem solidária.

A pesquisa de campo tem as mesmas características do estudo de campo, porém com rigor científico na coleta dos dados, na fundamentação teórica e análise de dados. A pesquisa de campo geralmente se dirige à comunidade como ambiente para coletar informações, testar hipóteses, observar comportamentos etc., não como local de intervenção para melhorar o que está sendo diagnosticado. Ainda que seja exigida a relevância social do problema que se quer investigar, o foco está no conhecimento (CHIZZOTTI, 1991). Nesse sentido, pesquisa de campo não é considerada aprendizagem solidária quando a comunidade é objeto de estudo ou laboratório de análise de onde se extrai informações para a pesquisa.

Atividades/projetos de aprendizagem solidária consistem em uma proposta educativa que tem como princípio identificar problemas sociais reais e propor soluções com atividades de intervenção social que de fato aconteçam. Trata-se, portanto, de uma pedagogia baseada em resolução de problemas. Nesse sentido, os alunos irão antever soluções possíveis, planejar e executar uma proposta de intervenção social, refletir sobre o que está acontecendo e redirecionar o percurso sempre que necessário; analisar os resultados almejados e obtidos tanto pedagógicos quanto sociais (ou ambientais, culturais etc.). Nessas atividades os estudantes participam de todas as etapas e com isso aprendem quando vivenciam, quando estudam mais, quando são responsáveis diretamente pelo trabalho desenvolvido com a comunidade. 
O respeito e o cuidado são compreendidos como valor e leitura de mundo, enquanto conhecimento. Essa é, aliás, a compreensão intrínseca sobre solidariedade relativa à aprendizagem solidária, considerada a partir da afirmação do outro para constituir a própria identidade, na horizontalidade das relações (MORI, 2013). No caso das situações de aprendizagem, a diferença se faz na maneira como se organizam as atividades educativas e o qual a visão de mundo que se pretende cunhar.

Para que seja possível articular conhecimento com propor soluções para problemas sociais reais, é preciso considerar alguns aspectos fundamentais, como o protagonismo dos estudantes e a qualidade do serviço solidário.

Exemplos de estudo de campo, pesquisa de campo e aprendizagem solidária: leituras e visitas a equipamentos públicos, promover debates envolvendo questões da atualidade durante as aulas são exemplos de possíveis atividades relativas aos estudos sobre questões da atualidade. Pesquisas de campo são aquelas em que pessoas ou seres vivos participam como grupos de testes ou de controle, em atividades passivas ou ativas (observação, entrevistas, grupos focais, entre outros). Aprendizagem solidária parte de situações pensadas junto à comunidade para atender a um problema social que lhe aflija, como promover a instalação de aquecedores solares para serem ligados a duchas de famílias que residem em zonas frias sem acesso à energia elétrica. Há estudo de caso, há escuta das reais necessidades da comunidade, há organização coletiva do trabalho, há método, há hipóteses de solução, há intervenção na realidade e resultados alcançados. Nesse percurso, tanto as aprendizagens do caminho quanto os resultados sociais são relevantes para a transformação desejada.

\section{A aprendizagem solidária e a Responsabilidade Social Universitária}

Segundo o Livro Verde sobre Responsabilidade Social e Instituições do Ensino Superior (ORSIES, 2018), a dinâmica da responsabilidade social das organizações tem assumido uma importância crescente no contexto institucional, independentemente do setor ou domínio de ação. Desde 2018, é requisito obrigatório cuidar dos impactos provocados pelas instituições, sendo que cada organização é convidada a concretizar o seu efetivo compromisso com a comunidade na qual está inserida.

Ao tomar como base o conhecimento emancipação e a proposta de aprendizagem solidária, esse contato direto com a comunidade acontece de maneira horizontal, fruto de um trabalho de escuta da comunidade. Produzir conhecimento nesse terreno significa 
desenvolver as competências da pesquisa, do estudo, do planejamento, da escuta, da colaboração, intervindo para transformar uma realidade que a própria comunidade quer mudar. Para isso é preciso promover a cultura do diálogo trabalhando pelo bem comum com responsabilidade.

A produção cientifica, tecnológica e cultural pode ser um espaço influenciador de políticas públicas, no qual os jovens podem aprender a partir de problemas reais com o objetivo de oferecer soluções concretas à sociedade.

Nesse sentido, vale considerar o que nos lembra Nieves Tapia (TAPIA, 2018) quando pontua que ao articular a aprendizagem solidária à responsabilidade social universitária, deve-se desejar que a excelência acadêmica seja confirmada pela qualidade da intervenção social que ela costura com a sociedade onde está inserida. O que se pretende é que haja articulação entre as áreas de conhecimento, pesquisa e extensão atendendo diretamente à sociedade.

O compromisso social das IES vem-se expressando em nossa região em formas de pesquisa e docência estreitamente articuladas com práticas de intervenção social, com Investigação-Ação Participativa (IAP), com a pedagogia de Aprendizagem e Serviço Solidário (ASS), entre outras (tradução livre). (TAPIA, 2018, p. 5)

Para que isso ocorra, o alinhamento curricular é necessário, pois os objetivos formativos e da comunidade precisam ser tratados com responsabilidade. Ele pode acontecer em diferentes níveis, desde no desenvolvimento de projetos de aprendizagem solidária em uma determinada matéria, como projeto interdisciplinar, envolvendo diferentes disciplinas, como projeto de conclusão de curso, ou ainda como proposta inserida no projeto político pedagógico universitário ${ }^{57}$. Nesta via, os saberes locais serão fundamentais para contextualizar, ensinar e iluminar as possibilidades de formação, conectando-se permanentemente com a reconstrução de um mundo possível, em favor da responsabilidade e cuidado mútuos.

Em síntese provocativa, destaco que os elementos que tencionam para melhorar a qualidade formativa estão alinhados ao comprometimento curricular com os princípios da responsabilidade social universitária. Maior será o impacto na formação desejada se a atividade de intervenção junto à comunidade se ela adentrar os saberes, se não tiver apartada como responsabilidade apenas da extensão, se estiver focada no assistencialismo

\footnotetext{
${ }^{57}$ Um exemplo significativo de aprendizagem e serviço solidário universitário é o trabalho desenvolvido pela Universidade Católica do Chile, para saber mais: http://ucsirveachile.uc.cl/aprendizaje-servicio. Acesso em 30/jan/2020.
} 
ou no aperfeiçoamento das habilidades técnicas dos formandos. A aprendizagem solidária como pedagogia baseada em problemas reais possibilita alinhar conhecimento, pesquisa e extensão pela construção do conhecimento emancipação solidariedade embebida no currículo, em favor da formação de cidadãos conscientes formados a partir do paradigma do cuidado, da autorregulação ética das ciências e das tecnologias, para que outra ordem mais justa e sustentável seja (re)construída, para que a educação sirva para aprender com os outros a cuidar de si, de todos e do planeta.

\section{Referências bibliográficas}

BOFF, L. Virtudes para um outro mundo possível: VI: A hospitalidade: direito e dever de todos. Petrópolis: Vozes, 2005.

Virtudes para um outro mundo possível: VII: Convivência, respeito,telerância. Petrópolis: Vozes, 2006.

CHIZZOTTI, A. Pesquisa em ciências humanas e sociais. São Paulo:Cortez, 1991.

COSTA, A. C. G. Protagonismo juvenil: adolescência, educação e participação democrática. Salvador: Fundação Odebrecht, 2000.

DEWEY, J. Democracia e educação: introdução à filosofia da educação. São Paulo: Nacional, 1979.

DUSSEL, E. 20 Teses de política. São Paulo: Expressão Popular, 2007.

FREIRE, P. Pedagogia da autonomia: saberes necessários à prática educativa. São Paulo: Paz e Terra, 1996.

2001.

Educação como prática da liberdade. $25^{\mathrm{a}}$ ed. Rio de Janeiro: Paz e Terra,

Sobre Educação (Diálogos). São Paulo: Paz e Terra, 1982.

FURCO, A. Service-Learning: A Balanced Approach to Experiential Education. University of California - Berkeley, Estados Unidos, 1996. Disponível em: http://kea.uovs.ac.za/faculties/documents/14/Service-Learning_Resources/Articles/Furco_1996_A_Balanced_Approach.pdf. Acesso_em:_10/fev/2010.

JORNAL DO BRASIL. A falsa filantropia precisa acabar. Disponível em: https://webcache.googleusercontent.com/search?q=cache:kpFMPf9MVPYJ:https://revis ta.tcu.gov.br/ojs/index.php/RTCU/article/view/480/531+\&cd=8\&hl=pt-

PT\&ct=clnk\&gl=pt. Acesso em em 10/jan/2020. 
ORSIES. Livro Verde sobre Responsabilidade Social e Instituições de Ensino Superior. Versão provisória para consulta pública, 2018. Disponível em: http://orsies.forum.pt/wp-content/uploads/2016/09/LivroVerde-vcompleta.pdf. Acesso em $10 /$ jul/2019.

MOREIRA. M.A. O que é afinal aprendizagem significativa? Disponível em: http://moreira.if.ufrgs.br/oqueeafinal.pdf Acesso em 10/jan/2020.

MORI, K.R.G. A solidariedade com prática curricular educativa. 2013. 227f. Tese (Doutorado em Educação: Currículo) - Pontifícia Universidade Católica de São Paulo.

SANTOS, B. S. Para um novo senso comum: a ciência, o direito e a política na transição paradigmática. V.1. A crítica da razão indolente: contra o desperdício da experiência. 7 ed. São Paulo: Cortez, 2009.

Pela mão de Alice. O social e o político na pós modernidade. São Paulo: Cortez Editora, 2010.

TAPIA, M.N. La solidaridad como pedagogía: el "aprendizaje-servicio" en la escuela. $2^{\text {a }}$ ed. Buenos Aires: Ciudad Nueva, 2001.

Aprendizaje y servicio solidario en el sistema educativo y las organizaciones juveniles. Buenos Aires: Ciudad Nueva, 2006.

El compromiso socialen el currículo de laEducación Superior. Ciudad Autónoma de Buenos Aires: CLAYSS, 2018.

TORO, B.A. El cuidado. El paradigma ético de la nueva civilización. Disponível em: https://www.las2orillas.co/wp-content/uploads/2014/11/EL-CUIDADO-COMOPARADIGMA.pdf Acesso em 14/jan/2020. 